\title{
ANALISIS PERFORMANSI WINCONNECT PADA JARINGAN PC CLONING UNTUK APLIKASI GAME ONLINE
}

\author{
Rizal Jihadus Solihin ${ }^{1}$, Defiana Arnaldy ${ }^{2}$, Syafedi Syafe'i ${ }^{3}$ \\ ${ }^{1,2,3}$ Teknik Informatika, Fakultas Sains dan Teknologi \\ Universitas Islam Negeri Syarif Hidayatullah Jakarta \\ Jl. Ir. H. Juanda No. 95 Ciputat 15412 Indonesia \\ ${ }^{1}$ rizal_js@yahoo.com \\ 2defiana@ymail.com \\ ${ }^{3}$ syafedi_sya@yahoo.com
}

Abstrak: Perkembangan game online semakin berkembang pesat, dengan kebutuhan spesifikasi hardware yang lebih tinggi. Kendala umum yang dihadapi oleh warnet atau game center adalah keterbatasan pada spesifikasi tinggi dari hardware. Salah satu solusi adalah menggunakan sistem PC Cloning.Untuk mengetahui performansi yang dihasilkan oleh sistem PC Cloning maka penulis melakukan pengujian terhadap sistem PC Cloning yang menggunakan aplikasi Winconnect. Pada penelitian ini penulis menggunakan metode simulasi General Network Design Process (GNDP). Pada penelitian ini penulis menggunakan CPU usage dan RAM usage sebagai parameter pengukuran performansi. Game online yang diuji adalah game Modoo Marbel, game DoTA, dan game Lost Saga. Setelah dilakukan pengujian maka diperoleh hasil bahwa pada sisi server terdapat peningkatan performansi ketika terjadi penambahan client dan penggunaan aplikasi. Pada saat menjalankan aplikasi game pada sistem PC Cloning dengan Winconnect, batasan spesifikasi game online yang bisa dijalankan hanya sampai pada spesifikasi DirectX versi 7.

Kata Kunci: PC Cloning, Winconnect, performansi, CPU Usage, RAM Usage

Abstract: In this paper, we describes the process of performance analysis of a PC Cloning networking systems, that is used to running simultaneous online game. The PC Cloning system uses Winconnect application. To perform test of proper hardware spesifications of the online games General Network Design Process (GNDP) simulation method was used. In this study, the author uses CPU usage and RAM usage as performance measurement parameters. Several online games were tested, there were Modoo Marble, DoTA, and Lost Saga. After testing then obtained results state that on the server side there is an increase in performance when the addition of client and application usage. At the time of running games application in PC Cloning using Winconnect, restriction for online game specifications that can run only up to the specifications of DirectX version 7.

Keywords: PC Cloning, Winconnect, performance, CPU usage, RAM usage

\section{PENDAHULUAN}

Permainan elektronik atau yang sering disebut dengan game online telah mengalami kemajuan yang sangat pesat. Ini bisa dilihat pada kota-kota besar, tidak terkecuali juga kota-kota kecil, banyak sekali warnet Game yang muncul. Game Online adalah game yang dapat dimainkan bersama dengan banyak orang di seluruh dunia hanya melalui koneksi internet saja.

\section{LANDASAN TEORI}

Game saat ini tidak seperti game terdahulu, jika dahulu game hanya bisa maksimal dimainkan dua orang, sekarang dengan kemajuan teknologi terutama jaringan internet, game bisa dimainkan 100 orang lebih sekaligus dalam waktu yang bersamaan seperti DoTA (Defend of The Ancient) ataupun DN (Dragon Nest). Walaupun game ditujukan untuk anak-anak, tidak sedikit pula orang dewasa kerap memainkannya bahkan tidak sedikit yang menjadikannya sebagai pekerjaan dan mendapat penghasilan dari bermain game.

Perbedaan komputer untuk browsing dengan komputer untuk game online adalah terletak pada spesifikasi hardware minimalnya. Sebagai contoh 
untuk browsing dibutuhkan minimal komputer pentium 3 sementara untuk game online dibutuhkan minimal komputer core 2 (duo) atau yang lebih tinggi. Jika spesifikasi komputer rendah maka game akan tetap berjalan tetapi tidak stabil.

Ada beberapa solusi yang bisa digunakan untuk mengatasi kekurangan yang terjadi pada Warnet game, salah satunya adalah dengan menggunakan PC cloning. PC cloning merupakan suatu bentuk efisiensi dalam penggunaan software dan hardware. Software berlisensi dapat diinstal dalam satu CPU host yang kemudian dikloning untuk penggunaan bersama beberapa client, untuk akses ke internet dan bermain game dengan banyak pemain. Salah satu layanan yang mendukung $P C$ cloning adalah Winconnect [1][2][4][5][6]. Winconnect dapat membagi resource yang dimiliki oleh satu komputer ke beberapa komputer lainnya. Hanya saja belum diketahui bagaimana performa yang diberikan oleh Winconnect pada layanan game online.

\section{METODE PENELITIAN}

Pada penelitian ini digunakan metode General Network Design Process (GNDP) [3] dengan 6 tahapan sebagai berikut :

\section{Assesing need and cost}

Pada tahap ini dijelaskan tentang hasil utama mengenai performansi pada sistem PC cloning menggunakan Winconnect untuk aplikasi perkantoran, multimedia, dan game.

\section{Select topologies and technologies}

Pada tahap ini dijelaskan tentang pemilihan topologi dan teknologi dalam penelitian ini. Pada penelitian ini digunakan topologi star dan didukung oleh teknologi kabel.

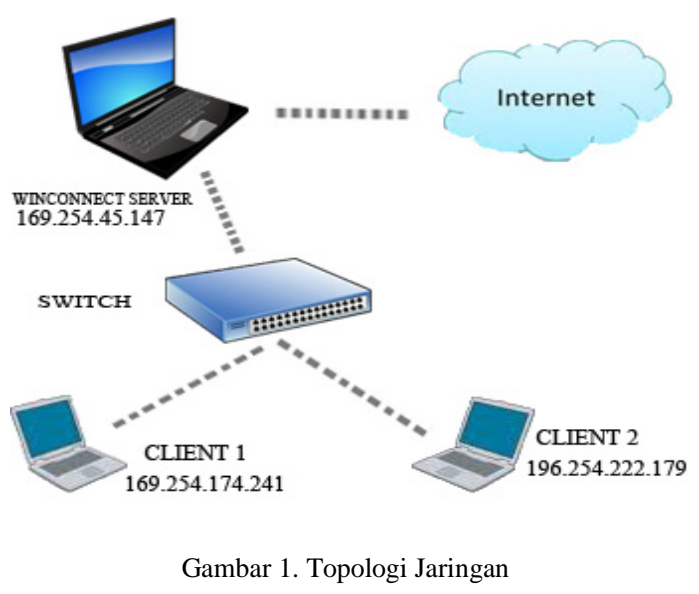

3. Model network workload

Pada tahap ini dijelaskan apa yang akan dibebankan pada jaringan. Sistem yang akan dibebankan yaitu sistem PC cloning menggunakan software Winconnect.

\section{Simulate behavior}

Pada tahap ini dilakukan simulasi sistem utama yaitu system $P C$ cloning menggunakan software Winconnect. Pada tahap ini dilakukan sebuah simulasi performansi terhadap system PC cloning menggunakan Winconnect tanpa menjalankan aplikasi.

\section{Perform sensitivity test}

Pada tahap ini dilakukan pengujian performansi terhadap sistem PC cloning yang menggunakan server Winconnect dengan menjalankan aplikasi perkantoran, multimedia dan game. Tahap pengujian sensitivitas dilakukan dengan 2 metrik: Process Explorer [7] dan Task Manager, dengan parameter yang diukur adalah RAM dan CPU usage.

\section{Rework design as needed}

Pada tahap ini akan dibahas tentang jumlah rata-rata hasil pengujian pada tahap Perform Sensitivity Test dan perbandingan antar client saat menggunakan aplikasi yang telah dijalankan, serta analisis game setelah diujikan. 


\section{IV.PEMBAHASAN}

Setelah dilakukan uji coba performansi sebanyak 10 kali ulangan pada sistem PC cloning menggunakan Winconnect, maka akan dihitung rata-rata dan analisa game. Alat untuk mengukur performansi menggunakan process explorer dan task manager, performansi yang diukur adalah RAM usage dan CPU usage dan menggunakan RDP (Remote Desktop Protocol) untuk mengakses dari sisi client ke sisi server [8].

a. Perhitungan rata-rata

Rumus yang digunakan untuk menghitung ratarata adalah rumus mean

$$
\bar{x}=\frac{x_{1}+x_{2}+x_{3}+\ldots+x_{n}}{n}
$$

Berikut adalah hasil grafik dari performansi.

- Process explore

Tabel 1. Aplikasi Perkantoran

\begin{tabular}{|c|c|c|c|}
\hline \multirow{2}{*}{ No } & \multirow{2}{*}{ Subjek } & \multicolumn{2}{|c|}{ Ms.Word \& Ms.Excel } \\
\cline { 3 - 4 } & & CPU usage & RAM usage \\
\hline 1 & 0 client & $3,40 \%$ & $1,1 \mathrm{~GB}$ \\
\hline 2 & 1 client & $13,36 \%$ & $1,4 \mathrm{~GB}$ \\
\hline 3 & 2 client & $29,76 \%$ & $1,6 \mathrm{~GB}$ \\
\hline
\end{tabular}

Tabel 2. Aplikasi Multimedia

\begin{tabular}{|c|c|c|c|}
\hline \multirow{2}{*}{ No } & \multirow{2}{*}{ Subjek } & \multicolumn{2}{|c|}{ Photoshop } \\
\cline { 3 - 4 } & & CPU usage & RAM usage \\
\hline 1 & 0 client & $3,40 \%$ & $1,1 \mathrm{~GB}$ \\
\hline 2 & 1 client & $19,06 \%$ & $1,5 \mathrm{~GB}$ \\
\hline 3 & 2 client & $31,91 \%$ & $1,6 \mathrm{~GB}$ \\
\hline
\end{tabular}

Tabel 3. Aplikasi Game 1

\begin{tabular}{|c|c|c|c|}
\hline \multirow{2}{*}{ No } & \multirow{2}{*}{ Subjek } & \multicolumn{2}{|c|}{ Zuma Deluxe } \\
\cline { 3 - 4 } & & CPU usage & RAM usage \\
\hline 1 & 0 client & $3,40 \%$ & $1,1 \mathrm{~GB}$ \\
\hline 2 & 1 client & $29,32 \%$ & $1,3 \mathrm{~GB}$ \\
\hline 3 & 2 client & $41,12 \%$ & $1,56 \mathrm{~GB}$ \\
\hline
\end{tabular}

Tabel 4. Aplikasi Game 2

\begin{tabular}{|c|c|c|c|}
\hline \multirow{2}{*}{ No } & \multirow{2}{*}{ Subjek } & \multicolumn{2}{|c|}{ Bejeweled Deluxe } \\
\cline { 3 - 4 } & & CPU usage & RAM usage \\
\hline 1 & 0 client & $3,40 \%$ & $1,1 \mathrm{~GB}$ \\
\hline 2 & 1 client & $31,79 \%$ & $1,3 \mathrm{~GB}$ \\
\hline 3 & 2 client & $45,15 \%$ & $1,5 \mathrm{~GB}$ \\
\hline
\end{tabular}

Tabel 5. Aplikasi Game 3

\begin{tabular}{|c|c|c|c|}
\hline \multirow{2}{*}{ No } & \multirow{2}{*}{ Subjek } & \multicolumn{2}{|c|}{ Modoo Marbel } \\
\cline { 3 - 4 } & & CPU usage & RAM usage \\
\hline 1 & 0 client & $3,40 \%$ & $1,1 \mathrm{~GB}$ \\
\hline 2 & 1 client & $34,59 \%$ & $1,5 \mathrm{~GB}$ \\
\hline 3 & 2 client & $53,41 \%$ & $2,0 \mathrm{~GB}$ \\
\hline
\end{tabular}

- Task manager

Tabel 6. Aplikasi Perkantoran

\begin{tabular}{|c|c|c|c|}
\hline \multirow{2}{*}{ No } & \multirow{2}{*}{ Subjek } & \multicolumn{2}{|c|}{ Ms.Word \& Ms. Excel } \\
\cline { 3 - 4 } & & CPU usage & RAM usage \\
\hline 1 & 0 client & $2,2 \%$ & $1,07 \mathrm{~GB}$ \\
\hline 2 & 1 client & $9,4 \%$ & $1,41 \mathrm{~GB}$ \\
\hline 3 & 2 client & $22,3 \%$ & $1,56 \mathrm{~GB}$ \\
\hline
\end{tabular}

Tabel 7. Aplikasi Multimedia

\begin{tabular}{|c|c|c|c|}
\hline \multirow{2}{*}{ No } & \multirow{2}{*}{ Subjek } & \multicolumn{2}{|c|}{ Photoshop } \\
\cline { 3 - 4 } & & CPU usage & RAM usage \\
\hline 1 & 0 client & $2,2 \%$ & $1,07 \mathrm{~GB}$ \\
\hline 2 & 1 client & $12,9 \%$ & $1,43 \mathrm{~GB}$ \\
\hline 3 & 2 client & $29,6 \%$ & $1,56 \mathrm{~GB}$ \\
\hline
\end{tabular}

Tabel 8. Aplikasi Game 1

\begin{tabular}{|c|c|c|c|}
\hline \multirow{2}{*}{ No } & \multirow{2}{*}{ Subjek } & \multicolumn{2}{|c|}{ Zuma Deluxe } \\
\cline { 3 - 4 } & & CPU usage & RAM usage \\
\hline 1 & 0 client & $2,2 \%$ & $1,07 \mathrm{~GB}$ \\
\hline 2 & 1 client & $24,6 \%$ & $1,29 \mathrm{~GB}$ \\
\hline 3 & 2 client & $34,7 \%$ & $1,49 \mathrm{~GB}$ \\
\hline
\end{tabular}

Tabel 9. Aplikasi Game 2

\begin{tabular}{|c|c|c|c|}
\hline \multirow{2}{*}{ No } & \multirow{2}{*}{ Subjek } & \multicolumn{2}{|c|}{ Bejeweled Deluxe } \\
\cline { 3 - 4 } & & CPU usage & RAM usage \\
\hline 1 & 0 client & $2,2 \%$ & $1,07 \mathrm{~B}$ \\
\hline 2 & 1 client & $24 \%$ & $1,27 \mathrm{~GB}$ \\
\hline 3 & 2 client & $37,7 \%$ & $1,51 \mathrm{~GB}$ \\
\hline
\end{tabular}

Tabel 10. Aplikasi Game 3

\begin{tabular}{|c|c|c|c|}
\hline \multirow{2}{*}{ No } & \multirow{2}{*}{ Subjek } & \multicolumn{2}{|c|}{ Modoo Marbel } \\
\cline { 3 - 4 } & & CPU usage & RAM usage \\
\hline 1 & 0 client & $2,2 \%$ & $1,07 \mathrm{~GB}$ \\
\hline 2 & 1 client & $28,1 \%$ & $1,47 \mathrm{~GB}$ \\
\hline 3 & 2 client & $47 \%$ & $1,89 \mathrm{~GB}$ \\
\hline
\end{tabular}

b. Grafik

Setelah mengetahui rata-rata dari performansi aplikasi perkantoran multimedia dan game maka diperoleh grafik sebagai berikut :

\section{1) Process explorer}

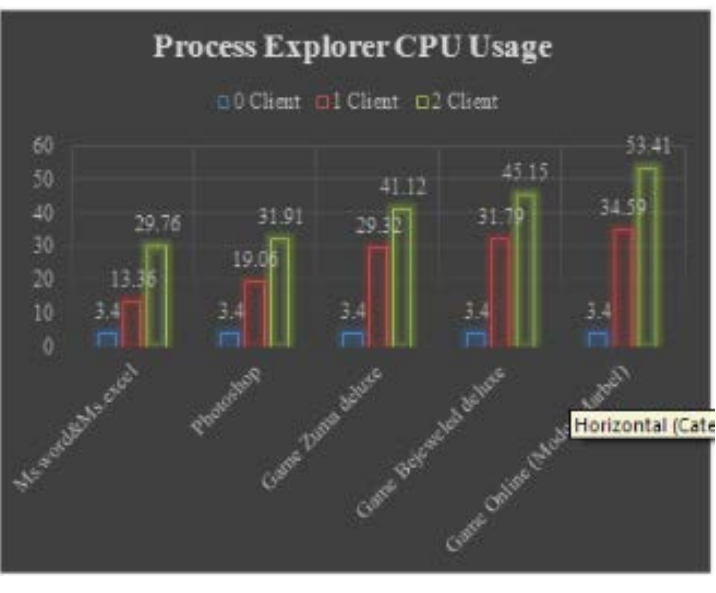

Gambar 2. CPU usage(pe) 
Jurnal Pseudocode, Volume 2 Nomor 1, Februari 2015, ISSN 2355 - 5920

Tabel. 11 Proses Explorer kenaikan persentasi CPU usage

\begin{tabular}{|l|l|l|}
\hline \multicolumn{1}{|c|}{ Aplikasi } & $\begin{array}{l}0-1 \\
\text { client } \\
(\%)\end{array}$ & $\begin{array}{l}0-2 \\
\text { client } \\
(\%)\end{array}$ \\
\hline MS. Word \& MS Excel & 292.90 & 775.20 \\
\hline Photoshop & 460.50 & 838.50 \\
\hline Game Zuma Deluxe & 762.30 & $1,109.40$ \\
\hline Game Bejeweled Deluxe & 835.00 & $1,227.90$ \\
\hline Game Online Modoo Marbel & 917.30 & $1,470.80$ \\
\hline
\end{tabular}

Berdasarkan gambar 2 di atas, untuk kenaikan persentase pada CPU usage yang dialami oleh server Winconnect dari 0 client ke 1 client yang berjalan dan dari 0 client ke 2 client sekaligus, perhitungannya sebagai berikut. Rumus kenaikan persentase adalah :

$\frac{\text { nilai kenaikan -nilai awal }}{\text { nilai awal }} \times 100$

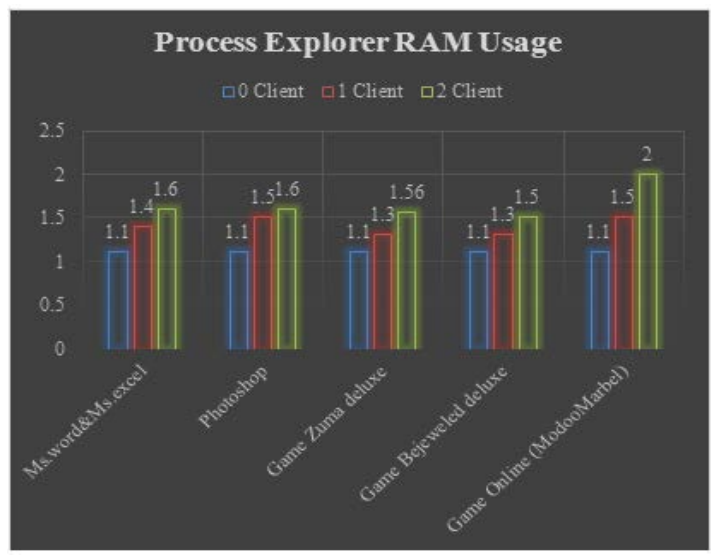

Gambar 3. RAM usage(pe)

Berdasarkan gambar 3 di atas, untuk kenaikan persentase pada RAM usage yang dialami oleh server Winconnect dari 0 client ke 1 client yang berjalan dan dari 0 client ke 2 client sekaligus, perhitungannya sebagai berikut. Rumus kenaikan persentase adalah

$$
\frac{\text { nilai kenaikan -nilai awal }}{\text { nilai awal }} \times 100
$$

Tabel. 12 Proses Explorer Kenaikan Persentasi RAM usage

\begin{tabular}{|l|l|l|}
\hline \multicolumn{1}{|c|}{ Aplikasi } & $\begin{array}{l}0-1 \\
\text { client (\%) }\end{array}$ & $\begin{array}{l}0 \quad-2 \\
\text { client } \\
(\%)\end{array}$ \\
\hline MS. Word \& MS Excel & 27.2 & 45.4 \\
\hline Photoshop & 36.3 & 45.4 \\
\hline Game Zuma Deluxe & 18.1 & 41.8 \\
\hline Game Bejeweled Deluxe & 18.1 & 36.3 \\
\hline $\begin{array}{l}\text { Game Online Modoo } \\
\text { Marbel }\end{array}$ & 36.3 & 81.8 \\
\hline
\end{tabular}

2) Task manager

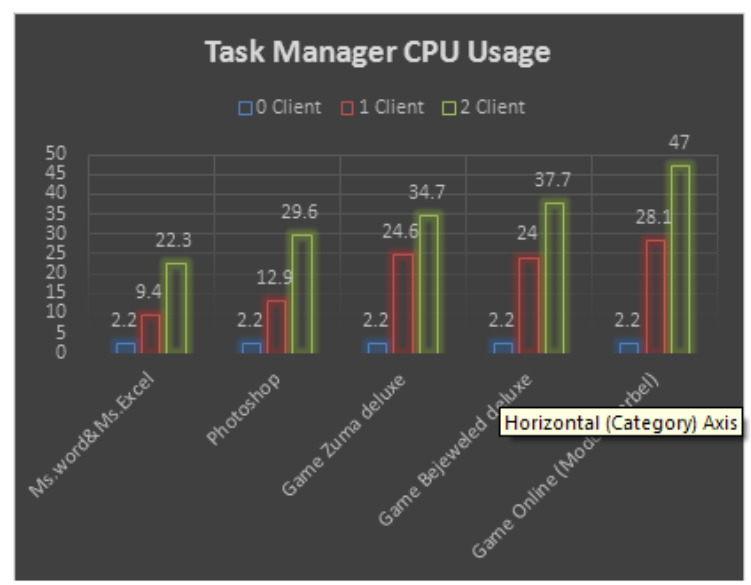

Gambar 4. CPU usage(tm)

Berdasarkan gambar 4 di atas, untuk kenaikan persentase CPU usage yang dialami oleh server Winconnect dari 0 client ke 1 client yang berjalan dan dari 0 client ke 2 client sekaligus, perhitungannya sebagai berikut. Rumus kenaikan persentase adalah

$$
\frac{\text { nilai kenaikan -nilai awal }}{\text { nilai awal }} \times 100
$$

Tabel. 13 Task Manager Kenaiikan Persentase CPU usage

\begin{tabular}{|l|l|l|}
\hline \multicolumn{1}{|c|}{ Aplikasi } & $\begin{array}{l}0-1 \\
\text { client } \\
(\%)\end{array}$ & $\begin{array}{l}0 \quad-2 \\
\text { client } \\
(\%)\end{array}$ \\
\hline MS. Word \& MS Excel & 327.2 & 913.6 \\
\hline Photoshop & 486.3 & 1245.4 \\
\hline Game Zuma Deluxe & 1018.1 & 1477.2 \\
\hline Game Bejeweled Deluxe & 990.9 & 1613.6 \\
\hline $\begin{array}{l}\text { Game Online } \\
\text { Modomarbel }\end{array}$ & 1177.2 & 2036.3 \\
\hline \multicolumn{2}{|r}{} \\
\hline
\end{tabular}




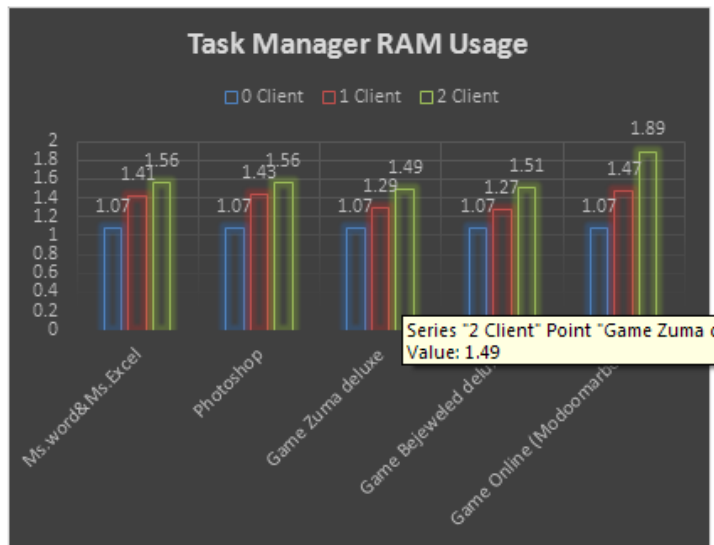

Gambar 5. RAM usage(tm)

Berdasarkan gambar 5 di atas, untuk kenaikan persentase RAM usage yang dialami oleh server Winconnect dari 0 client ke 1 client yang berjalan dan dari 0 client ke 2 client sekaligus, perhitungannya sebagai berikut. Rumus kenaikan persentase adalah

$$
\frac{\text { nilai kenaikan -nilai awal }}{\text { nilai awal }} \times 100
$$

Tabel. 14 Task Manager Kenaikan Persentase RAM usage

\begin{tabular}{|l|l|l|}
\hline \multicolumn{1}{|c|}{ Aplikasi } & $\begin{array}{l}0-1 \\
\text { client } \\
(\%)\end{array}$ & $\begin{array}{l}0-2 \\
\text { client } \\
(\%)\end{array}$ \\
\hline MS. Word \& MS Excel & 31.7 & 45.7 \\
\hline Photoshop & 33.6 & 45.7 \\
\hline Game Zuma Deluxe & 20.5 & 39.2 \\
\hline Game Bejeweled Deluxe & 18.6 & 41.1 \\
\hline $\begin{array}{l}\text { Game Online Modoo } \\
\text { Marbel }\end{array}$ & 37.3 & 76.6 \\
\hline
\end{tabular}

Hasil performansi server Winconnect dengan menggunakan alat pengukur Task manager dan process explorer menunjukkan bahwa setiap penggunaan client yang menggunakan aplikasi akan meningkatkan performa pada sisi server Winconnect.

\section{c. Analisis game}

Pada penelitian ini game yang diujikan adalah game DoTA, Lost Saga, Modoo Marbel, Zuma Deluxe, Bejeweled Deluxe. Yang dapat berjalan pada penelitian ini hanya game Zuma Deluxe,
Bejeweled Deluxe dan Modoo Marbel. Berikut adalah gambar tampilan game DoTA dan Lost Saga yang tidak berjalan.

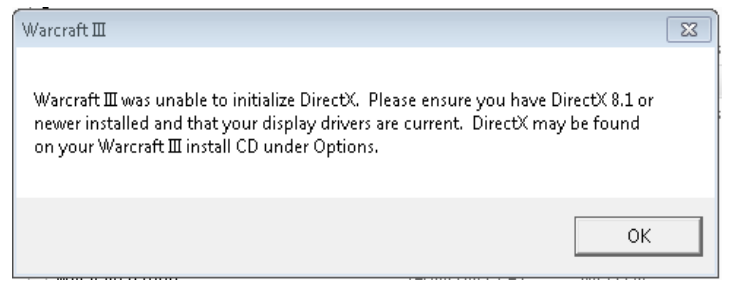

Gambar 6. Informasi Game DoTA tidak berjalan

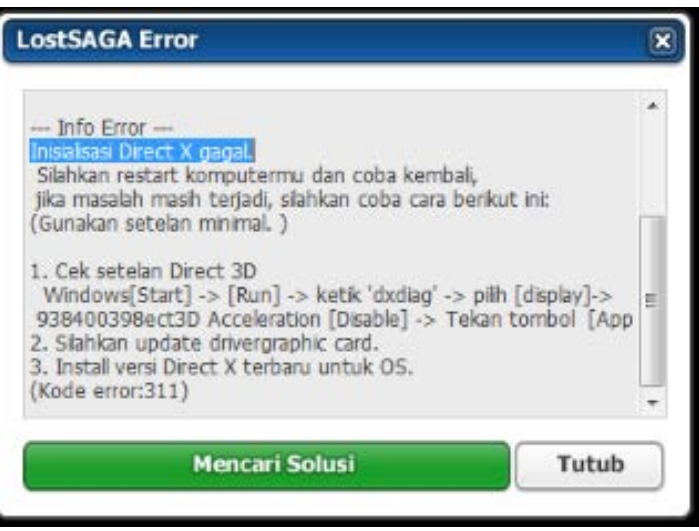

Gambar 7. Informasi Lost Saga

Berdasarkan gambar 6 dan 7, game DoTA dan Lost Saga memerlukan directX versi yang dibutuhkan oleh game tersebut agar sistem dapat berjalan di server Winconnect minimum kebutuhan sistem dari setiap game harus terpenuhi. Berikut adalah kebutuhan sistem minimum dari setiap game pada penelitian ini.

1) Zuma Deluxe

\begin{tabular}{|c|c|c|}
\hline Requirements & $\begin{array}{c}\text { Minimum } \\
\text { Requirements }\end{array}$ & $\begin{array}{c}\text { Recommended } \\
\text { Requirements }\end{array}$ \\
\hline OS & Windows 98/2000 & Windows XP/7 \\
\hline CPU & $\begin{array}{c}\text { Pentium II } \\
350 \mathrm{MHz} \\
\text { Processor }\end{array}$ & or higher \\
\hline RAM & $64 \mathrm{MB}$ & or higher \\
\hline DirectX & DirectX 7 & or Higher \\
\hline \multicolumn{3}{|c|}{ Network: Offline } \\
\hline
\end{tabular}

Gambar 8. Zuma Deluxe

2) Bejewel Deluxe

\begin{tabular}{|c|c|c|}
\hline Requirements & $\begin{array}{c}\text { Minimum } \\
\text { Requirements }\end{array}$ & $\begin{array}{c}\text { Recommended } \\
\text { Requirements }\end{array}$ \\
\hline OS & Windows $98 / 2000$ & Windows XP/7 \\
\hline CPU & Pentium II & or higher \\
& $350 \mathrm{MHz}$ \\
Processor & or higher \\
\hline RAM & $22 \mathrm{MB}$ & or higher \\
\hline DirectX & DirectX 7 & \\
\hline \multicolumn{3}{|c|}{ Network: Offline } \\
\hline
\end{tabular}

Gambar 9. Bejeweled Deluxe 
3) Modoo Marbel

\begin{tabular}{|c|c|c|}
\hline Requirements & $\begin{array}{c}\text { Minimum } \\
\text { Requirements }\end{array}$ & $\begin{array}{c}\text { Recommended } \\
\text { Requirements }\end{array}$ \\
\hline OS & $\begin{array}{c}\text { Windows } \\
\text { XP/Vista }\end{array}$ & $\begin{array}{c}\text { Windows } \\
\text { XP/Vista/7/8 }\end{array}$ \\
\hline CPU & Pentium 3 & $\begin{array}{c}\text { Dual-core } \\
2.60 \mathrm{GHz}\end{array}$ \\
\hline RAM & $256 \mathrm{MB}$ & $512 \mathrm{MB}$ \\
\hline DirectX & DirectX 7.0 & DirectX 7.0 \\
\hline \multicolumn{3}{|c|}{ Network : Online } \\
\hline
\end{tabular}

Gambar 10. Modoo Marbel

4) DoTA

\begin{tabular}{|c|c|c|}
\hline Requirements & $\begin{array}{c}\text { Minimum } \\
\text { Requirements }\end{array}$ & $\begin{array}{c}\text { Recommended } \\
\text { Requirements }\end{array}$ \\
\hline OS & Windows XP & Windows 7 \\
\hline CPU & Pentium 3 & or higher \\
\hline RAM & $128 \mathrm{MB}$ & or higher \\
\hline DirectX & DirectX 8.1 & DirectX 8.1 \\
\hline \multicolumn{3}{|c|}{ Network: Online/Offline } \\
\hline
\end{tabular}

Gambar 11. DoTA

5) Lost Saga

\begin{tabular}{|c|c|c|}
\hline Requirements & $\begin{array}{c}\text { Minimum } \\
\text { Requirements }\end{array}$ & $\begin{array}{c}\text { Recommended } \\
\text { Requirements }\end{array}$ \\
\hline OS & Windows XP & Windows 7 \\
\hline CPU & Pentium 4 1.2 Ghz & $\begin{array}{c}\text { Pentium 42.4 } \\
\text { Ghzor higher }\end{array}$ \\
\hline RAM & 256MB & 512 or higher \\
\hline DirectX & DirectX 9.0c & DirectX 9.0c \\
\hline \multicolumn{3}{|c|}{ Network : Online } \\
\hline \multicolumn{3}{|c}{ Gambar 12. Lost Saga }
\end{tabular}

Seharusnya tidak terdapat masalah pada sisi server Winconnect jika kebutuhan minimum game sudah terpenuhi. Gambar 13 dan Gambar 14 menunjukkan hal tersebut.

Dari Gambar 13 dan Gambar 14 terdapat utility bernama DirectX diagnostic tool yang disediakan oleh Microsoft, tool ini tidak terdapat di Start Menu pada Windows versi berapapun. Cara mudah untuk menggunakannya adalah dengan membuka dialog Run dari Start Menu, ketik dxdiag dan kemudian klik OK. Directx diagnostic tool ini berfungsi untuk mengetahui kemampuan komputer dalam segi memori, prosesor, atau hal lainnya.

Berdasarkan hasil analisis kebutuhan sistem diketahui bahwa masalah yang terdapat saat menjalankan game DoTA dan Lost Saga adalah karena memerlukan DirectX yang sesuai kebutuhan oleh game tersebut. Karena komputer server sudah melebihi kebutuhan atau mencukupi kebutuhan sistem yang dibutuhkan oleh game DoTA dan Lost Saga maka sisi komputer server tidak ada masalah.

Dari sisi client, Winconnect tidak membebani sisi client. Client pada server Winconnect menggunakan RDP (remote desktop protocol) untuk me-remote ke server, ketika client terkoneksi pada server dan menjalankan game yang hasilnya tidak dapat berjalan seperti pada gambar 6 dan 7 , maka diadakan pengecekan ulang menggunakan DirectX diagnostic tool pada sisi client pada saat menjalankan game DoTA dan Lost Saga. Hasil menunjukkan bahwa pada menu tab "System" DirectX diagnostic tool tidak terdapat perbedaan dengan sisi server akan tetapi terdapat perubahan pada menu tab “display”seperti Gambar 14.

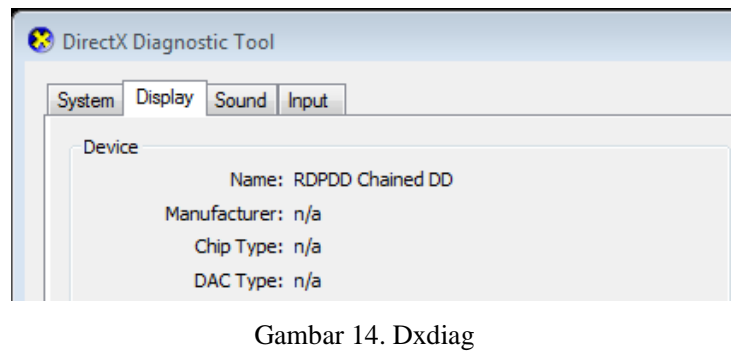

Berdasarkan pengujian, diketahui bahwa server Winconnect mampu menjalankan game DirectX 7, tetapi gagal dalam menjalankan game DoTA dan Lost Saga.

Server Winconnect membagi resource berupa RAM dan Processor, karena server Winconnect menggunakan RDP (Remote Desktop Protocol) maka pada kasus di atas untuk fungsi DirectX, pembagian resource tergantung aturan yang dimiliki oleh RDP. 


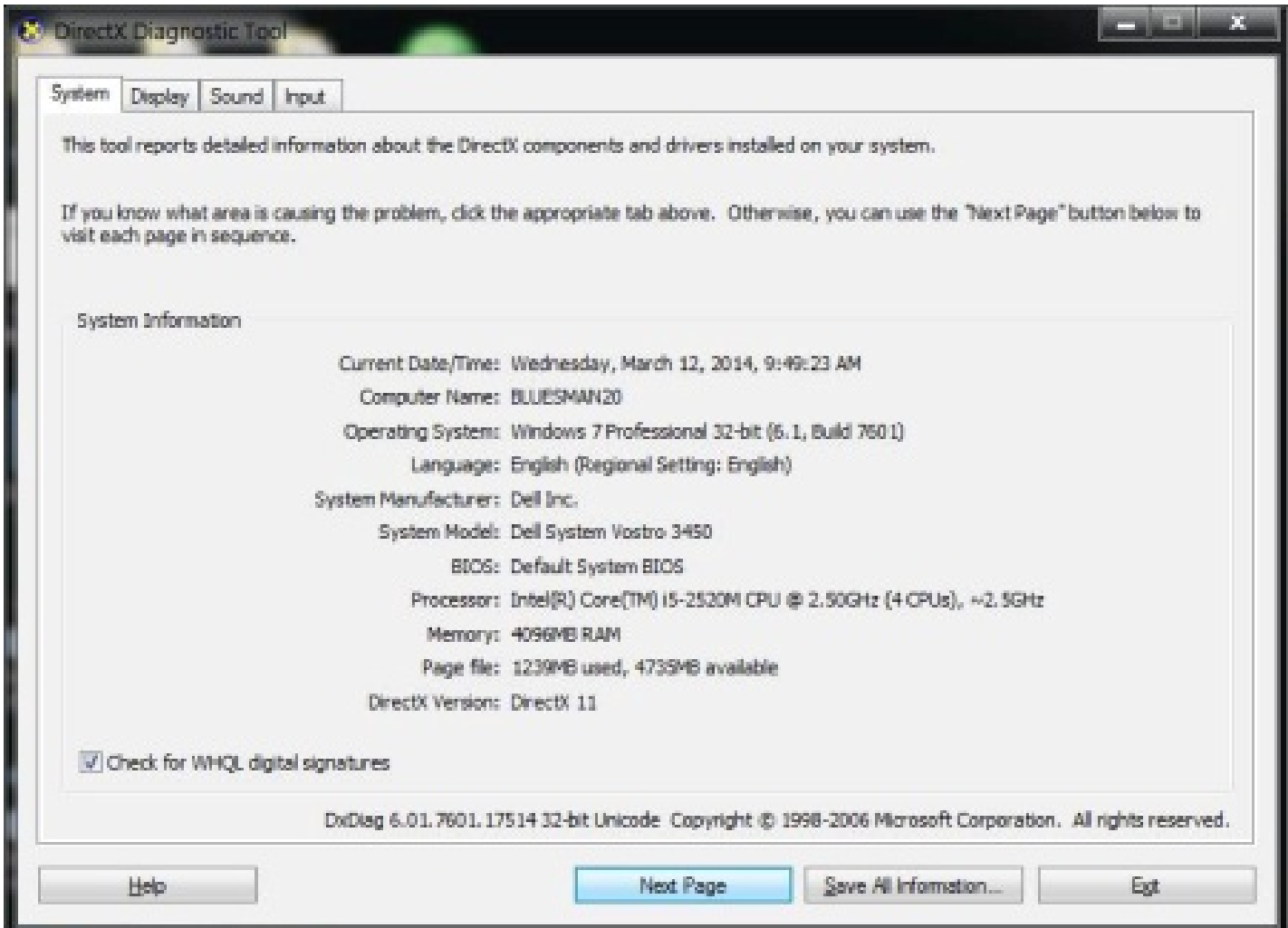

Gambar13. Komputer server (1)

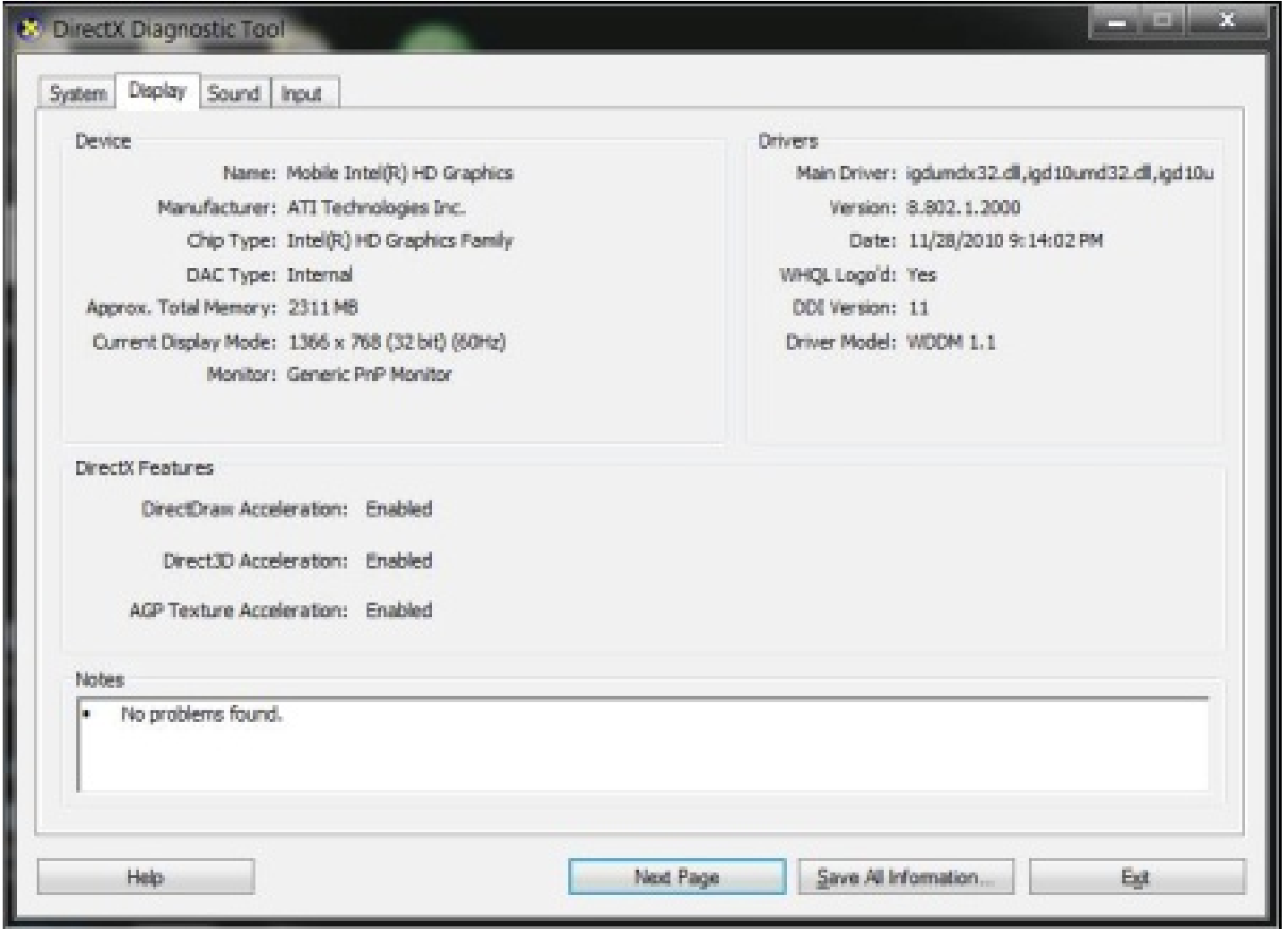

Gambar 14. Komputer server (2) 


\section{KESIMPULAN}

Berdasarkan hasil pengujian yang telah dilakukan maka dapat ditarik kesimpulan bahwa sistem PC Cloning menggunakan Winconnect mampu menjalankan game online dengan keterbatasan game yang memerlukan DirectX versi 7, sebab Winconnect mengikuti aturan pada RDP

(Remote Desktop Protocol) dan hanya membagi resource berupa RAM dan Processor.

\section{REFERENSI}

[1] Faisal, Lisal. 2006. Menghemat Dengan Membangun Jaringan PC Cloning Menggunakan Winconnect. Diperoleh 22 November 2013, dari http://ikc.depsos.go.id/populer/lisalfaisal-pccloning.php

[2] Joko, Mumpuni I. dan Wardono, Adisuryo. 2006. Meningkatkan Kemampuan Jaringan Komputer dengan PC Cloning System. Yogyakarta : Andi.
[3] Cisco. Indonetwork Design Guide: Introduction. http://docswiki.cisco.com. Diperoleh 14 ktober 2014

[4] Pratama Rizky Agung., Peryadi., Sularso Anang. 2011. Analisis Performansi Winconnect Dengan Betwin Pada Jaringan PC Cloning. Diperoleh 22 November 2013, dari www.politekniktelkom.ac.id/portofolio.../30207039

[5] Putro, Sulistyo., Triyono, Ramadian Agus., Purnama, Bambang Eka. 2013. Implementasi Jaringan Komputer Kloning Pada Sekolah Menengah Kejuruan Kanisius Bharata Karanganyar. Diperoleh 22 November 2013, dari

http://ijns.org/journal/index.php/ijns/article/download/ $114 / 113$

[6] ThinClient. 2013. User Guide Winconnect. Diperoleh 20 Oktober 2013, dari www.thinclient.com.

[7] Micorosoft. 2013. Process Explorer. Diperoleh 15 November 2013, dari http://technet.microsoft.com/idid/sysinternals/bb896653.

[8] Wisnuargo, Ferry., Prihandoko. Perbandingan Kinerja Remote Desktop Team Viewer dengan Xtralogic RDP Client pada Warnet Ferrykom Cybernet. Diperoleh 18 September 2013, dari http://repository.gunadarma.ac.id/bitstream/123456789/6 740/1/JURNAL\%20SKRIPSI.pdf 